Volume 7 No. 2, Juli-Desember 2020

P-ISSN: 2406-808X // E-ISSN: 2550-0686

https://journal.iainlangsa.ac.id/index.php/ikhtibar

https://doi.org/10.32505/ikhtibar.v7i2.616

\title{
UPAYA GURU DALAM MENINGKATKAN HASIL BELAJAR PENDIDIKAN AGAMA ISLAM DI SEKOLAH DASAR
}

\author{
Novia Hardiyanti, Wiwin Arbaini Mahyuningsih, Asri Karolina \\ Institut Agama Islam Negeri Curup \\ diyaoviacurup@gmail.com
}

\begin{abstract}
Abstrak
Penelitian ini bertujuan menemukan gambaran tentang upaya yang dilakukan oleh guru dalam meningkatkan hasil belajar Pendidikan Agama Islam siswa kelas IV SDN 156 yang terletak di Desa Bangun Jaya, Kabupaten Rejang Lebong. Penelitian ini menggunakan pendekatan kualitatif dan data terkumpul melalui teknik observasi dan wawancara. Setelah data terkumpul maka dilakukan analisis dengan tahapan sebagai berikut: pemilihan data, menyajian dan penarikan kesimpulan. Penelitian ini memperoleh kesimpulan bahwa upaya yang dilakukan oleh guru dalam meningkatkan hasil belajar PAI siswa antara lain: meminta kepala sekolah untuk menampah jam di luar jam pelajaran PAI; melakukan komunikasi dengan wali siswa untuk mengingatkan anak mereka agar mengulang pelajaran di rumah; melakukan evaluasi sebelum dan sesudah pelajaran; memilih pendekatan/metode yang menarik bagi siswa; dan menggunakan media pembelajaran agar memudahkan menjelaskan materi dan mudah difahami oleh siswa dan menggunakan metode hadiah dan hukuman. Gambaran hasil pembelajaran PAI siswa kelas IV tergolong baik karena seluruh nilai siswa pada tahun ajaran 2019-2020 terlihat dari hasil semester mereka telah mencapai standar KKM yang ditetapkan.
\end{abstract}

Kata Kunci: Upaya Guru, Hasil Belajar Siswa

\section{TEACHERS' EFFORTS TO IMPROVE ISLAMIC EDUCATION LEARNING OUTCOMES AT A PRIMARY SCHOOL}

\begin{abstract}
The present study aimed at finding out the efforts made by teachers to improve the outcomes of Islamic education (PAI) learning undertaken by IV grade students at SDN 156 in Bangun Jaya village, Rejang Lebong regency. This study used a qualitative approach, and the data were collected using observation and interview techniques. After data collection, analyses were carried out with the following stages: selecting data, presenting data, and drawing conclusion. This study concluded that the efforts made by teachers in improving students' learning outcomes of PAI included: asking the principal to add learning hours outside PAI teaching hours; communicating with students' parents to remind their children of rehearsing lessons at home; making evaluations before and after the lessons; choosing approaches or methods that appealed to students; making use of learning media to make it easier to explain the
\end{abstract}


materials so that the materials were easily understood by students; and using the reward and punishment methods. The description of PAI learning outcomes for the fourth grade students was quite good because all students'values in the school year of 2019-2020 could be seen from the results of their semester which had reached the specified KKM standard.

Keywords: Teachers' Efforts, Students' Learning Outcomes

\section{Pendahuluan}

Pendidikan menduduki tempat yang sangat penting sebagai pembentuk ruang moral bagi penentuan tujuan hidup manusia, untuk mewujudkan pendidikan nasional yang berdasarkan Pancasila dan Undang-undang 1945 yang bertujuan untuk mengembangkan potensi peserta didik agar menjadi manusia yang beriman dan bertakwa kepada Tuhan Yang YME, terbentuk suatu masyarakat yang adil dan makmur yang merata baik material maupun spiritual yang berdasarkan Pancasila yang merdeka, bersatu, aman, dan tenteram ${ }^{1}$. Pendidikan dan pengajaran agama di sekolah dasar dan menengah adalah merupakan bagian yang sangat penting dalam rangka mencapai tujuan pendidikan nasional tersebut. Bahkan tersebut merupakan tujuan bangsa Indonesia yakni pembangunan bukan hanya sekadar pemenuhan keutuhan materi melainkan adanya pemenuhan kebutuhan material dan spiritual.

Untuk mencapai hal tersebut pemerintah menyelenggarakan suatu sistem pendidikan nasional sebagaimana tercantum dalam UU No. 20 Tahun 2003 tentang pendidikan nasional, yang menyatakan bahwa: "Pendidikan adalah usaha sadar dan terencana untuk mewujudkan suasana belajar dan proses pembelajaran agar peserta didik secara aktif mengembangkan potensi dirinya untuk memiliki kekuatan spiritual keagamaan, pengendalian diri, kepribadian, kecerdasan, akhlak mulia, serta ketermpilan yang diperlukan dirinya, masyarakat, bangsa negara" 2 .

Dalam Islam, pendidikan adalah pemberi corak hitam putihnya perjalanan hidup seseorang, karena Islam mayikini bahwa manusia terlahir ke dunia membawa potensi kesucian yang harus dikembangkan oleh lingkungan dan lingkungan pendidikan ${ }^{3}$. Oleh karena itu ajaran agama Islam menetapkan bahwa pendidikan merupakan salah satu kegiatan yang wajib hukumnya bagi pria dan wanita dan berlangsung seumur hidup bahkan semenjak dari buaian hingga ajal dating ${ }^{4}$. Kedudukan tersebut secara tidak langsung telah menempatkan pendidikan sebagai bagian yang tidak terpisahkan dengan hidup dan kehidupan umat manusia. Demikian halnya dengan pendidikan Islam dikalangan umat Islam merupakan salah satu bentuk manifistasi dari ciri-ciri hidup untuk melestarikan, mengalihkan dan menanamkan dan menstransformasikan nilai-nilai Islam tersebut kepada pribadi generasi penerusnya sehingga

1 Juliansyah Juliansyah, "Kritik Filosofis Atas Tujuan, Visi, dan Misi Mempertanyakan Mutu Pendidikan Nasional," JURNAL LENTERA BISNIS 1, no. 1 (2017): 65-77; Syarifah Normawati and SIti Marpuah, "Kerangka Pembangunan Karakter dalam Pembentukan Kreativiti Remaja Di Sekolah Menengah Pertama Kota Batam,” Human Sustainability Procedia, 2018.

2 Margi Wahono, "Pendidikan Karakter: Suatu Kebutuhan Bagi Mahasiswa Di Era Milenial," Integralistik 29, no. 2 (2018): 145-151; Lukman Hakim, "Pemerataan Akses Pendidikan Bagi Rakyat Sesuai Dengan Amanat Undang-Undang Nomor 20 Tahun 2003 Tentang Sistem Pendidikan Nasional," EduTech: Jurnal Ilmu Pendidikan Dan Ilmu Sosial 2, no. 1 (2016), https://doi.org/10.30596/edutech.v2i1.575.

3 Idi Warsah, "Interkoneksi Pemikiran Al-Ghazāli Dan Sigmund Freud Tentang Potensi Manusia,"

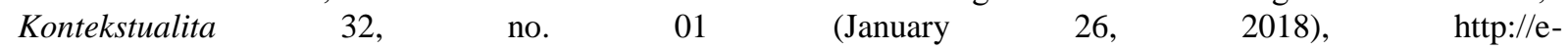
journal.lp2m.uinjambi.ac.id/ojp/index.php/Kontekstualita/article/view/30; Idi Warsah, "Pendidikan Keimanan Sebagai Basis Kecerdasan Sosial Peserta Didik: Telaah Psikologi Islami," Psikis : Jurnal Psikologi Islami 4, no. 1 (2018): 1-16, https://doi.org/10.19109/psikis.v4i1.2156.

${ }^{4}$ Fajar Kurniawan, "Pengembangan Teori Pendidikan Islam Perspektif Muhammad Jawwad Ridla (Religius Konservatif, Religius Rasional, Pragmatis Instrumental)," At-Ta'lim: Media Informasi Pendidikan Islam 18, no. 1 (2019): 223-242.

Al-Ikhtibar: Jurnal Ilmu Pendidikan Volume 7 No. 2, Juli-Desember 2020 
nilai-nilai kultural religius yang dicita-citakan dapat berfungsi dan berkembang dalam masyarakat dari waktu ke waktu.

Figur seorang guru dalam dunia pendidikan selalu menjadi topik pembicaraan karena guru merupakan salah satu faktor pendidikan yang sangat penting, oleh karena itu guru mempunyai peran penting dalam proses pembelajaran ${ }^{5}$. Guru sangat berperan dalam membantu perkembangan peserta didik untuk mewujudkan tujuan hidupnya secara optimal ${ }^{6}$. Guru yang berkaitan langsung dalam pencapaian tujuan pendidikan, khususnya pendidikan agama Islam di sekolah ${ }^{7}$.

Oleh karena itu guru pendidikan agama Islam dituntut untuk mampu menjalankan tugasnya sebagai guru PAI yang profesional. Karena setiap guru guru bukan hanya bertanggung jawab menyampaikan materi pelajaran kepada murid, tetapi juga membentuk kepribadian seorang peserta didik dengan keteladanan, yang pada akhirnya peserta didik memiliki kepribadian yang paripurna ${ }^{8}$.

Tugas guru dalam pembelajaran agama Islam meliputi menyampaikan materi, membimbing, melatih, memotivasi, memfasilitasi, dan mengevaluasi hasil pembelajaran. Sehubungan dengan hal itu guru agama Islam dituntut untuk mempunyai upaya-upaya yang bagus demi peningkatan mutu pendidikan agama Islam, namun seorang guru pastilah mempunyai waktu yang relatif terbatas untuk membimbing peserta didik disekolah.

Dalam realitas struktur kurikulum sekolah menengah pendidikan agama Islam (PAI) hanya 3 x 35 menit (3 jam pelajaran) dalam satu minggu. Apakah dengan waktu tersebut guru Pendidikan Agama Islam mampu melaksanakan tugasnya dengan baik. Padahal ruang lingkup materi PAI yang dikutip oleh Muhaimin dkk, dalam buku Paradigma Pendidikan Agama Islam pada dasarnya mencakup lima unsur pokok, yaitu Al Qur'an, keimanan, akhlak, fiqh, dan lebih menekankan pada perkembangan ajaran agama, ilmu pengetahuan dan kebudayaan ${ }^{9}$. Selain itu pendidikan agama Islam sangat mempunyai peran penting dalam kehidupan seharihari karena dalam pembelajaran agama Islam terdapat hukum yang mengatur tentang tata cara menjalani kehidupan sehari-hari dan juga memberikan tuntunan bagi semua agar memperoleh kebahagiaan dunia dan akhirat ${ }^{10}$.

5 Idi Warsah and Muhamad Uyun, "Kepribadian Pendidik: Telaah Psikologi Islami," Psikis : Jurnal Psikologi Islami 5, no. 1 (June 18, 2019): 62-73, https://doi.org/10.19109/Psikis.v5i1.3157; Idi Warsah and Nuzuar Nuzuar, "Analisis Inovasi Administrasi Guru Dalam Meningkatkan Mutu Pembelajaran (Studi Man Rejang Lebong)," Edukasi 16, no. 3 (2018): 294572; Wasis Ridwan and Ode Moh Man Arfa Ladamay, "Peran Guru Pendidikan Agama Islam dalam Pembinaan Akhlakul Karimah Peserta Didik di Sma Muhammadiyah 8 Cerme Gresik," TAMADDUN 21, no. $1 \quad$ (April 4, 2020): 067-076, https://doi.org/10.30587/tamaddun.v21i1.1378.

6 Pupu Saeful Rahmat, "Peran Pendidikan Dalam Menyiapkan Generasi Emas," Pendidikan Guru Sekolah Dasar S1 1, no. 01 (2016); Muh Zein, "Peran Guru Dalam Pengembangan Pembelajaran," Inspiratif Pendidikan 5, no. 2 (2016): 274-285.

${ }^{7}$ Rahmat Hidayat, Muhammad Sarbini, and Ali Maulida, "Peran Guru Pendidikan Agama Islam Dan Budi Pekerti Dalam Membentuk Kepribadian Siswa SMK Al-Bana Cilebut Bogor,” Prosa PAI: Prosiding Al Hidayah Pendidikan Agama Islam 1, no. 1B (2018): 146-157; Elihami Elihami and Abdullah Syahid, "Penerapan Pembelajaran Pendidikan Agama Islam Dalam Membentuk Karakter Pribadi Yang Islami," Edumaspul: Jurnal Pendidikan 2, no. 1 (2018): 79-96.

${ }^{8}$ Aep Saepul Anwar, "Pengembangan Sikap Profesionalisme Guru Melalui Kinerja Guru Pada Satuan Pendidikan MTs Negeri 1 Serang," Andragogi: Jurnal Pendidikan Islam Dan Manajemen Pendidikan Islam 2, no. 1 (2020): 147-173; Muhamad Anwar, Menjadi Guru Profesional (Prenada Media, 2018); Isna Wardatul Bararah, "Profesionalisme Dosen dalam Perspektif Islam Dan Kontribusinya Terhadap Mutu Perguruan Tinggi," Jurnal MUDARRISUNA: Media Kajian Pendidikan Agama Islam 8, no. 2 (2018): 245-257; Ambros Edu, Florianus Arifin, and Mikael Nardi, Etika Dan Tantangan Profesionalisme Guru (Alfabeta Bandung, 2017).

${ }^{9}$ Muhammad Hatim, "Kurikulum Pendidikan Agama Islam Di Sekolah Umum," EL-HIKMAH: Jurnal Kajian Dan Penelitian Pendidikan Islam 12, no. 2 (2018): 140-163.

10 Ade Imelda, "Implementasi Pendidikan Nilai Dalam Pendidikan Agama Islam," Al-Tadzkiyyah: Jurnal Pendidikan Islam 8, no. 2 (2017): 227-47, https://doi.org/10.24042/atjpi.v8i2.2128; Muhammad Al-Ikhtibar: Jurnal Ilmu Pendidikan Volume 7 No. 2, Juli-Desember 2020 
Memang diakui bahwa salah satu indikator keberhasilan belajar terlihat kepada kemampuan yang bersifat kognitif, seperti nilai yang diperoleh oleh siswa pada setiap evaluasi yang dilakukan oleh guru. Namun dalam konteks materi penididikan Islam tidak cukup melihat keberhasilan hanya pada sisi kognitif saja namun pada keseluruhan aspek ${ }^{11}$. Apapun bentuk evaluasi yang dilakukan oleh guru, misalnya dalam bentuk latihan, maupun evaluasi akhir semester tujuannya adalah untuk memperlihat gambaran hasil siswa dalam proses pembelajaran. Hal ini terlihat ketika observasi awal dan bertemu langsung dengan guru PAI SDN 165 Bangun Jaya Rejang Lebong, diperoleh informasi bahwa memang materi PAI cukup disenangi oleh siswa, namun terdapat beberapa materi yang sulit diserap oleh siswa. Seperti materi-materi yang di dalamnya terdapat ayat al-Qur'an maupun hadis nabi. ${ }^{12}$

Sehubungan dengan hal tersebut, penulis tertarik untuk menganalisis lebih dalam tentang upaya Guru Dalam Meningkatkan hasil belajar Pendidikan Agama Islam di SDN 165 Bangun Jaya" karena Pendidikan Agama Islam di tingkat Sekolah Dasar mempunyai peran dan fungsi yang strategis dalam membentuk kepribadian generasi penerus agama, bangsa, dan negara di masa mendatang.

\section{Metode Penelitian}

Peneitian ini menggunakan pendekataan kualitatif. Pendekatan kualitatif merupakan prosedur penelitian yang menghasilkan data deskriptif berupa kata-kata atau pernyataan lisan dari orang atau perilaku yang dapat diamati yang diarahkan pada latar individu ${ }^{13}$. Penelitian ini difokuskan di SD N 165 kelas IV Desa Bangun Jaya Rejang Lebong, yang merupakan salah satu Sekolah Dasar yang mayoritas gurunya melakukan upaya perbaikan mutu pendidikan, termasuk dalam bidang Pendidikan Agama Islam. Obyek penelitian ini adalah aktivitas yang dilakukan oleh guru PAI di SDN Bangun Jaya tersebut sekaligus sebagai informan kunci penelitian ini, sementara susyeknya adalah siswa.

Agar penelitiaan ini diperoleh data yang benar dan dapat dipertanggung jawabkan, maka diperlukan metode dalam pengumpulan data yang relevan dengan permasalahan yang ada. Adapun metode yang digunakan adalah observasi dan wawancara ${ }^{14}$. Setelah data terkumpul melalui kedua pendekatan tersebut, tahap selanjutnya adalah analisis data dengan

Fathurrohman, "Pengembangan Budaya Religius Dalam Meningkatkan Mutu Pendidikan," Ta'allum: Jurnal Pendidikan Islam 4, no. 1 (2016): 19-42; Mohammad Roesli, Ahmad Syafi'i, and Aina Amalia, "Kajian Islam Tentang Partisipasi Orang Tua Dalam Pendidikan Anak," Jurnal Darussalam: Jurnal Pendidikan, Komunikasi Dan Pemikiran Hukum Islam 9, no. 2 (April 29, 2018): 332-45, https://doi.org/10.30739/darussalam.v9i2.234.

11 Ainna Khoiron Nawali, "Dampak Penerapan Kurikulum Kementerian Agama dan Kurikulum Pesantren Terhadap Peningkatan Hasil Belajar PAI di MAN Yogyakarta," Al-Ikhtibar: Jurnal Ilmu Pendidikan 5, no. 1 (2018): 555-575; Aset Sugiana, "Pengembangan Kurikulum Pendidikan Agama Islam Dan Implementasinya di MTs Nurul Ummah Yogyakarta," Jurnal Pendidikan Agama Islam 16, no. 1 (June 5, 2019): 17-34, https://doi.org/10.14421/jpai.jpai.2019.161-02; Hesti Yulianti, Cecep Darul Iwan, and Saeful Millah, "Penerapan Metode Giving Question And Getting Answer Untuk Meningkatkan Hasil Belajar Peserta Didik Pada Mata Pelajaran Pendidikan Agama Islam," Jurnal Penelitian Pendidikan Islam,[SL] 6, no. 2 (2018): 197216; Irfan Taufik, "Penerapan Model Pembelajaran Contextual Teaching and Learning (CTL) Dalam Meningkatkan Hasil Belajar," IQRO: Journal of Islamic Education 2, no. 2 (2019): 163-174.

${ }^{12}$ Hasil Observasi pada tanggal, 12 Januari 2020 di SD N 165 Bangun Jaya Rejang lebong

${ }^{13}$ Lexi J. Moleong, Methodology of Qualitative Research (Bandung: Remaja Rosda Karya, 2010); Eko Sugiarto, Menyusun Proposal Penelitian Kualitatif: Skripsi dan Tesis: Suaka Media (Diandra Kreatif, 2017); Dedi Supriadi, "Pokoknya Kualitatif: Dasar-Dasar Merancang Dan Melakukan Penelitian Kualitatif," Jakarta: PT. Dunia Pustaka Jaya, 2011.

${ }^{14}$ Kathryn Roulston, “Analysing Interviews," The SAGE Handbook of Qualitative Data Analysis, 2014, 297-312; Conny R. Semiawan, Metode Penelitian Kualitatif (Grasindo, 2010); Chaedar Alwasilah, "Pokoknya Kualitatif: Dasar-Dasar Rancangan Dan Melakukan Penelitian Kualitatif,” Jakarta: Pustaka, 2011.

Al-Ikhtibar: Jurnal Ilmu Pendidikan Volume 7 No. 2, Juli-Desember 2020 
menggunakan pendekatan Miles, Huberman dan Saldana dengan tahapan sebagai berikut: reduksi data, penyajian data dan menarikan kesimpulan ${ }^{15}$.

\section{Hasil dan Pembahasan}

\section{Hasil Penelitian}

Dalam pembahasan pada sub bab ini, penyusun akan memaparkan hasil wawancara dengan guru tentang upaya yang dilakukan oleh guru PAI dalam meningkatkan pembelajaran PAI siswa kelas IV SDN 165 Bangun Jaya ,Rejang Lebong.

\section{a. Upaya guru dalam meningkatkan hasil belajar PAI}

Dalam rangka memperoleh informasi tentang upaya yang dilakukan oleh guru dalam meningkatkan hasil belajar siswa kelas IV SDN 165 Bangun Jaya, perlu dipertanyakan hal-hal seperti: "Hal apa yang dilakukan guru dalam meningkatkan hasil belajar siswa? Menurut tanggapan guru PAI SDN 165 Bangun Jaya:

"Kami melakukan beberapa Strategi, strategi yang kami lakukan dalam meningkatkan hasil belajar PAI siswa antara lain: melakukan penambahan jam belajar di sekolah; memperbaiki metode mengajar yang menarik agar siswa lebih termotivasi memperhatikan saat kami menjelaskan; meminta kepala sekolah untuk menyediakan media yang menarik dan memudahkan kami dalam menjelaskan materi bahkan kami berusaha menyiapkan sendiri media dari rumah agar pelaksanaan pembelajaran yang kami lakukan tidak monoton dan membosankan siswa. Kemuadian setiap akhir pertemuan kami meminta siswa untuk latihan menjawab soal, kami juga melakukan strategi hadiah dan hukuman, hadiah ini memancing murid agar lebih aktif lagi dalam pembelajaran PAI,bisa berupa uang, buku, bagi siswa yang nilainya paling tinggi,dan kami juga melakukan hukuman bagi siswa yang nilainya rendah yaitu berupa harus menghpal surat atu menulis ayat alquran,dan bgtu juga selam jam pelajaran, kami sering menerapkan hukuman bagi siswa yang sulit diatur, ribut membuat gaduh, ${ }^{16}$

Berdasarkan pemaparan di atas jelaslah bahwa strategi merupakan cara-cara yang dilakukan oleh guru PAI dalam upaya meningkatkan hasil belajar siswa kelas IV SDN 165 Bangun Jaya. Melalui strategi yang dilakukan guru, dengan harapan agar siswa dapat memperoleh pelajaran dengan baik ketika guru menyampaikan materi pelajaran PAI. Selain itu juga strategi dimaksud untuk memudahkan guru melaksanakan tugasnya dalam proses pembelajaran di kelas.

Pertanyaan berikutnya adalah sebagai berikut: Apakah setiap memulai dan menutup pelajaran saudara memberikan evaluasi kepada siswa? Menurut infromasi dari guru PAI tentu paparnya: "Seperti telah kami singgung tadi, memang setiap memulai pelajaran kami melakukan evaluasi singkat guna memperdalam materi yang telah lalu. Begitu juga ketika mengahiri materi pelajaran tentu kami lakukan evaluasi seperti latihan menjawab soal yang berkaitan dengan materi yang telah kami sampaikan tadi". ${ }^{17}$

Pendapat di atas memandang perlu evaluasi dalam setiap pembelajaran. Tentu tujuannya adalah untuk mengetahui sejauh mana pencapaian yang diperoleh oleh siswa setelah mengikuti materi pembelajaran PAI di kelas. Jika melihat informasi di atas, evaluasi juga memberikan koreksi bagi pelaksanaan pembelajaran yang dilakukan oleh guru selama

15 Matthew B. Miles, A. Michael Huberman, and Johnny Saldaña, Qualitative Data Analysis: A Methods Sourcebook. 3rd (Thousand Oaks, CA: Sage, 2014); Matthew B. Miles, M. A. Huberman, and Johnny Saldana, "Drawing and Verifying Conclusions. Qualitative Data Analysis: A Methods Sourcebook," 2014; Miles, Huberman, and Saldana.

${ }^{16}$ Wawancara dengan ibu Wike di ruang guru pada saat istirahat, Selasa, 7 Februari 2020

17 Wawancara, Selasa, 7 Februari 2020 
kurun waktu tertentu sehingga guru dapat berbenah diri dan mencari inovasi baru agar proses pembelajaran ke depan semakin lebih baik.

Dalam menemukan informasi lebih akurat untuk menjawab pertanyaan penelitian pertama ini, perlu juga ditanyakan: "Apakah saudari menjalin kerja sama dengan orang tua agar membantu mengontrol anak di rumah untuk mengulang pelajaran?"

Secara formal kami memang tidak menjalin kerja sama kepada wali siswa untuk berusaha meningkatkan hasil belajar siswa pada materi PAI ini. Karena mengingat mata pelajaran PAI sebetulnya tidak terlalu sulit bagi siswa. Namun kami tentu berkomukasi dengan wali siswa agar memperhatikan anak-anak di rumah untuk mengulang pelajarannya". ${ }^{18}$

Secara teoretis maupun praktis komunikasi antara lembaga pendidikan dengan lingkungan menjadi hal yang penting. Apalagi komunikasi antara guru PAI dengan wali siswa di SDN 165 Bangun Jaya. Tanpa adanya komukasi yang baik antara pusat pendidikan ini, proses pendidikan tidak akan berjalan dengan baik. Bantuan orang tua di rumah untuk memberikan kontrol dan membimbing siswa akan dapat menghantarkan mereka kepada hasil belajar yang baik. Dengan kata lain tanggungjawab keberhasilan sebuah proses pendidikan bukanlah hanya dibebankan kepada sekolah saja (dalam hal ini kepada guru) tapi semua pihak harus merasa bertanggungjawab. Dengan rasa tanggungjawab dari semua pihak, tentu kualitas pendidikan akan menjadi lebih baik.

Pertanyaan selanjutnya adalah "Apakah saudari menambah jam pelajaran di waktu yang lain untuk meningkatkan hasil belajar PAI di sekolah?

"Menambah jam di luar jam pelajaran PAI tentu kami lakukan. Hal ini merupakan salah satu strategi yang kami lakukan guna meningkatkan hasil belajar mereka. Untuk itu kami meminta izin kepada kepala sekolah untuk memberitahukan kepada setiap wali murid agar mereka mengatahui ada program les tambahan untuk materi PAI. Namun kami tidak memungut biaya, karena pembelajaran tambahan tersebut hanya satu hari dalam satu minggu dan terfokus pada kemampuan membaca, menulis arab, dan praktek". ${ }^{19}$

Pertanyaan terakhir pada uraina masalah pertama adalah: Apakah saudara memanfaatkan media dalam pembelajaran PAI? Informasi yang disampaikan oleh informan adalah sebagai berikut: "Iya, dalam setiap pembelajaran berlangsung kami menggunakan media, meskipun media itu kami siapkan di rumah dengan membuat sendiri di rumah, jika materinya praktik maka kami membeli media visual yang dijual di toko percetakan, dan kami membuaktnya sebaik dan semenarik munkin serta harus mudah di pahami oleh murid". ${ }^{20}$

Merujuk kepada argumentasi di atas, diperoleh gamabaran data bahwa media pembelajaran merupakan hal yang penting selaian metode dan kompetensi guru dalam memberikan materi. Media merupakan alat yang memudahkan guru menyampaikan materi kepada siswa, media juga dapat memudahkan siswa dalam memahami materi yang disampaikan oleh guru. Guru yang profesional akan dapat memilih media yang sesuai dengan materi yang akan dibahas dan pemilihan media juga mempertimbangkan kondisi psikologis siswa, mereka akan senang dengan media yang digunakan oleh guru dan akan pada akhirnya para siswa akan memperoleh hasil yang maksimal dari pembelajaran yang diberikan oleh guru, mereka akan mudah mengingat jika menggunakan media, serta bisa dengan cepat mempraktekkan nya.

Berpijak pada paparan di atas, tergambar beberapa upaya yang dilakukan oleh guru PAI SDN 165 Bangun Jaya dalam rangka meningkatkan hasil belajar siswa kelas IV pada

\footnotetext{
${ }^{18}$ Wawancara, Selasa, 7 Februari 2020

${ }^{19}$ Wawancara, Selasa, 7 Februari 2020

${ }^{20}$ Wawancara, Selasa, 7 Februari 2020
} 
mata pelajaran PAI antara lain: meminta kepala sekolah untuk menampah jam di luar jam pelajaran PAI; melakukan komunikasi dengan wali siswa untuk mengingatkan anak mereka agar mengulang pelajaran di rumah; melakukan evaluasi sebelum dan sesudah pelajaran; memilih pendekatan/metode yang menarik bagi siswa; dan menggunakan media pembelajaran agar memudahkan menjelaskan materi dan mudah difahami oleh siswa.

\section{b. Gambaran hasil belajar PAI siswa kelas IV SDN}

Untuk memperoleh hasil yang akurat tentang gambaran hasil belajar siswa selama tahun ajaran 2019-2020 maka peneliti memberikan pertanyaan-pertanyaan sebagai berikut: "Bagaimana gambaran kemampuan siswa kelas IV dalam menerima materi PAI di SDN 165 Bangun Jaya?" berdasarkan informasi dari informan:

"Alhamdulillah kami merasa bersyukur bahwa upaya yang kami lakukan dalam meningkatkan hasil belajar siswa kelas IV SDN 165 Bangun Jaya semua mencapai KKM. Memang ada beberapa materi pelajaran yang sulit mereka ikuti seperti ketika diminta membaca ayat al-Qur'an atau hadis, dan materi yang berkenaan dengan huruf hijaiyah. Hal tersebut karena masih ada sebagian siswa kelas IV belum lulus Iqra'. Namun demikian mereka kami dorong dan motivasi agar tidak berputus asa sehingga mereka dapat menjawab materi yang diberikan saat ujian dengan baik". ${ }^{21}$

Dengan demikian, jelaslah bahwa indikator keberhasilan proses pembelajaran yang diberikan oleh guru adalah keberhasilan siswa secara kolistik baik dalam bentuk kognitif, afektif maupun psikomotorik. Melaluai nilai yang diperoleh siswa dalam setiap evaluai, guru akan memberikan penekanan kepada siswa akan materi yang belum mereka kuasai.

Materi apa saja yang paling sulit diserap oleh setiap siswa dalam pembelajaran PAI? "Sebagai mana telah disinggung tadi, materi yang saya temukan dianggap sulit oleh siswa ketika diminta untuk membaca lafaz-lafaz yang berkenaan dengan huruf-huruf hijaiyah dan praktek lainya seperti shalat karena bnyak yang terkendala membaca ayat alquran. Selebihnya mereka dapat mengikuti dengan baik."22

Pertanyaan terakhir pada tujuan penelitian kedua ini adalah sebagai berikut: "Bagaimana respons wali siswa terhadap hasil belajar PAI siswa yang rendah?"

"Nah berkenaan dengan respons wali siswa kami mengatakan sepertinya biasa-biasa saja berkenaan dengan hasil belajar siswa khususnya pada materi PAI ini (menurut pendapat guru PAI). Lebih lanjut beliau menagatakan "bisa jadi karena mereka menganggap bahwa pelajaran PAI bukanlah pelajaran inti dan tidak akan menjadi stardar kelulusan siswa kelak. Jadi yah mereka memandang biasa-biasa saja hasil baik maupun tidak baik yang peroleh oleh anak-anak mereka."23

Beberapa informasi yang tergambar berdasarkan hasil wawancara di atas, jelaslah bahwa hasil pembelajaran PAI siswa kelas IV tergolong baik karena seluruh nilai siswa pada tahun ajaran 2019-2020 terlihat dari hasil semester mereka telah mencapai standar KKM sebagaimana terlampir pada lampiran skripsi ini. meskipun diakui bahwa masih ada sebagian siswa menemui kesulitan ketika bertemu dengan materi PAI yang berkaitan dengan lafazlafaz hurup hijaiyah.

\section{c. Kendala yang ditemui guru dalam upaya meningkatkan hasil belajar siswa}

Untuk memperoleh informasi tentang kendala yang ditemui oleh guru dalam upaya meningkatkan hasil belajar PAI siswa kelas IV SDN 165 Bangun Jaya, perlu ditertanyakan hal-hal sebagai berikut: "Bagaimana motivasi siswa dalam mengikuti pelajaran PAI di kelas?

${ }^{21}$ Wawancara dengan ibu Wike di ruang guru pada saat istirahat, 17 Februari 2020

22 Wawancara, Selasa, 17 Februari 2020

${ }^{23}$ Wawancara, Selasa, 17 Februari 2020

Al-Ikhtibar: Jurnal Ilmu Pendidikan Volume 7 No. 2, Juli-Desember 2020 
"Memang pengalaman kami dalam mengajar PAI di sekolah ini, terutama kelas IV, motivasi belajar siswa kurang. Ini terlihat ketika mereka mengikuti pembelajaran PAI, kami menjelaskan materi anak-anakpun sibuk mengobrol di belakang. Sehingga hal tersebut menyadarkan kami, mungkin saja cara kami mengajar kurang menarik. Nah kami pernah mencoba melakukan menelitian tindakan kelas (PTK) dengan menerapkan metode bermain kepada siswa, ternyata mereka cukup bersemangat mengikut pelajaran PAI. Kami berkesimpulan bahwa cara atau pendeketan kami menjadi hal yang membuat mereka tidak fokus dan semangat mengikuti materi PAI. ${ }^{24}$

Berdasarkan informasi yang dipaparkan di atas, jelaslah bahwa motivasi siswa adalah hal sangat penting dalam mecapai keberhasilain siswa pada proses belajar. Motivasi bisa dipengaruhi oleh dua faktor; dari dalam diri siswa maupun dari luar diri siswa. Motivasi yang datang dari diri siswa seperti kesadaran akan pentingnya pelajaran tersebut bagi diri mereka masing-masing, sementara motivasi yang datang di luar diri siswa, seperti sikap guru, cara mengajar guru dan hal-hal yang datang dari luar diri siswa yang dapat memberikan semangat bagi siswa dalam mengikuti pembelajaran di kelas maupun belajar di rumah.

Pertanyaan selanjutnya adalah" Bagaimana resfons kepala sekolah dengan jam tambahan PAI yang dilakukan oleh saudara?"

Sebagaimana telah kami sampaikan beberapa hari yang lalu, untuk menambah jam pelajaran PAI di luar jam pejaran formal, kami meminta izin terlebih dahulu kepada kepala sekolah, alhamdulillah beliau memberikan izin dengan catatan tidak boleh memungut biaya, tidak memberatkan kami sendiri dan siswa, dan tidak mengganggu jam pelajaran yang lain. ${ }^{25}$

Hal ini di perkuat oleh hasil wawancara bersama bapak Muh. Sodik,S.Pd.SD selaku kepala sekolah beliau menjelaskan "Iya di sekolah ini ada jam tambahan les selama satu kali dalam semiggu yang di usulkan dari guru PAI dan saya mengizinkan hal tersebut agar murid semakin pintar dalam membaca dan menulis ayat al-quran agar hasilnya lebih maksimal,"26

Pelaksanaan pembelajaran yang dilakukan oleh guru, juga perlu dukungan dari pimpinan sekolah, guru yang lain dan tenaga tata usaha (TU). Program apapun yang dilaksanakan oleh guru dalam meningkatkan hasil belajar siswa sulit akan terlaksana tanpa dukungan dari pimpinan sekolah, baik dari dukungan moral, pembiayaan maupun dukungan sarana dan prasarana yang di sediakan sekolah.

Kepala sekolah sebagai manajer dan supervisor dapat memberikan bimbingan kepada guru sekaligus memberikan evaluasi kepada guru dalam setiap pelaksanaan pembelajaran. Hal ini penting, agar guru dapat sungguh-sungguh menciptakan inovasi dalam pelaksanaan pembelajaran.

Pertanyaan berikutnya adalah "Apakah metode yang saudara gunakan pada materi PAI membosankan siswa?"

"Harus kami akui, pada awalnya memang pengetahuan dan kurangnya perhatian kami pada kondisi siswa kurang, sehingga kami beru menyadari bahwa metode dan pendekatan kami kurang memberikan kesan menarik bagi siswa. Setelah kami evaluasi dan kami berusaha memperbaiki pembelajaran dengan melakukan strategi termasuk menggunakan metode yang melibatkan siswa dalam belajar, siswa menjadi merasa dilibatkan dan motivasi mereka untuk mengikuti materi PAI yang selama ini membosankan bagi mereka semakin meningkat."27

\footnotetext{
${ }^{24}$ Wawancara, Selasa, 17 Februari 2020

${ }^{25}$ Wawancara, Selasa, 17 Februari 2020

${ }^{26}$ Wawancara dengan kepala sekolah Bapak Muh. Sodik,S.Pd.SD di ruang guru pada saat istirahat, 19 Februari 2020

${ }^{27}$ Wawancara dengan ibu wike di ruang guru pada saat istirahat, 17 Februari 2020

Al-Ikhtibar: Jurnal Ilmu Pendidikan Volume 7 No. 2, Juli-Desember 2020
} 
Sudah menjadi kewajiban setiap guru untuk kreatif memilih metode yang akan digunakan dalam proses pembelajaran. Penerapan metode pembelajaran tentu harus mempertimbangkan kondisi siswa. dengan kata lain pertu dipertimbangkan apakah metode yang akan diterapkan betul-betul akan membuat proses pembelajaran menjadi efektif ada efisien, juga metode yang digunakan akan menarik perhatian siswa dalam menerima materi yang diberikan sehingga pembelajaran yang diberikan berkesan dan dapat meningkatkan hasil belajar siswa.

Pertanyaan terakhir adalah "Kendala apa yang paling urgen saudara temui dalam upaya meningkatkan hasil belajar PAI di SDN 165 Bangun Jaya?"

"Ketita kami ditanya tentang kendala yang ditemukan dalam upaya meningkatkan hasil belajar PAI siswa kelas IV SDN 165 Bangun Jaya sebetulnya banyak . Mulai dari kurangnya pengetahuan dan kretifitas kami dalam menyajikan materi pelajaran, media yang tersedia di sekolah, sempitnya waktu pelajaran PAI, kurangnya motivasi orang tua siswa masing-masing dan kemampuan siswa itu sendiri. Namun yang sering kami temukan adalah masih ada siswa yang belum mampu membaca al-Qura'n sehingga ketika kami meminta siswa untuk menghafal materi yang berlafaz hurup hijaiyah masih ada yang mengalami kesulitan. ${ }^{28}$

Berdasarkan beberapa informasi yang telah dipaparkan di atas, tergambar bahwa, upaya guru dalam meningkatkan hasil belajar siswa mengalami kendala antara lain karena; media pembelajaran yang kurang tersedia di sekolah sehingga menghendaki guru PAI untuk membuat dan menyiapkan media sendiri dari rumah; kurangnya motivasi dan bimbingan orang tua di rumah dan masih ada beberapa siswa yang belum bisa dengan baik membaca lafaz-lafaz hijaiyah sehingga guru kesulitan ketika meminta siswa untuk menghafal materi yang berlafaz arab.

\section{Pembahasan}

Guru adalah sosok pendidik yang sebenarnya. Dalam UU RI Nomor 14 tahun 2005 Tentang guru adalah pendidik professional dengan tugas utama sebagai mendidik, mengajar, membimbing, membimbing, mengarahkan, melatih, menilai ndan mengevaluasi peserta didik pada pendidikan anak usia dini, jalur pendidikan formal, pendidikan dasar, dan pendidikan menengah ${ }^{29}$.

Profesi keguruan merupakan profesi yang sangat berat dalam hal tanggung jawabnya baik di dunia maupun di akhirat. Seorang guru harus mampu manjadi suri tauladan bagi anak didiknya, baik dari segi tingkah lakunya, ucapannya dan seterunya ${ }^{30}$. Hal ini seuai dengan semboyan klasik: "Guru itu untuk digugu dan ditiru artinya digugu perkatannya dan ditiru

\footnotetext{
${ }^{28}$ Wawancara, Selasa, 17 Februari 2020 Ibid.

${ }^{29}$ Anwar, "Pengembangan Sikap Profesionalisme Guru Melalui Kinerja Guru Pada Satuan Pendidikan MTs Negeri 1 Serang"; Nur Illahi, "Peranan Guru Profesional Dalam Peningkatan Prestasi Siswa Dan Mutu Pendidikan Di Era Milenial," Asy-Syukriyyah 21, no. 1 (2020): 1-20.

30 Rahendra Maya, "Esensi Guru Dalam Visi-Misi Pendidikan Karakter," Edukasi Islami: Jurnal Pendidikan Islam 2, no. 03 (2017); Farizal Marliu, Otong Surasman, and Taufan Taufan, "Keteladanan Guru Dan Pendidikan Dalam Keluarga Terhadap Kepribadian Muslim Siswa DI MTs Pondok Pesantren Al-Husainy Kota Bima," TAJDID: Jurnal Pemikiran Keislaman Dan Kemanusiaan 4, no. 1 (2020): 29-40; Marwati Marwati and M. Ridwan Said Ahmad, "Peran Guru Dalam Menerapkan Pendidikan Karakter di Sma Islam Al-Azhar 12 Makassar," JURNAL SOSIALISASI, 2019, 57-62; Evinna Cinda Hendriana and Arnold Jacobus, "Implementasi Pendidikan Karakter di Sekolah Melalui Keteladanan dan Pembiasaan,” JPDI (Jurnal Pendidikan Dasar Indonesia) 1, no. 2 (October 31, 2017): 25-29, https://doi.org/10.26737/jpdi.v1i2.262; Miss Saining Samae and Istanto, "Pengaruh Keteladanan Guru Dalam Menanamkan Nilai Akhlak Siswa di Madrasah Tsanawiyah Negeri 2 Surakarta" (PhD Thesis, Universitas Muhammadiyah Surakarta, 2017); Indra Zakaria, "Penanaman Sikap Sopan Santun Melalui Keteladanan Guru Di Smp Negeri 1 Buduran Kabupaten SidoarjO,” Kajian Moral Dan Kewarganegaraan 2, no. 4 (2016).
}

Al-Ikhtibar: Jurnal Ilmu Pendidikan Volume 7 No. 2, Juli-Desember 2020 
perbuatannya"31. Guru sebagai pekerja profesional, sekurang-kurangnya harus menguasai empat kompetensi dengan baik. Empat, kompetensi itu sebagai berikut ${ }^{32}$ :

a. Kompetensi pedagogik yaitu: dalam standar nasional pendidikan, penjelasan pasal 28 ayat 3 butir A dikemukakan bahwa kompetensi pedagogic adalah kemampuan mengelola pembelajaran peserta didik, perencangan dan pelaksanaan pembelaaran, evaluasi hasil belajar, dan pengembangan peserta untuk mengaktualisasikan berbagai potensi ang dimilikinya.

b. Kompetensi kepribadian, dalam standar nasional pendidikan, penjelasan pasal 28 ayat 3 butir B dikemukakan bahwa kompetensi kepribadian adalah kemampuan kepribadian adalah kemampuan kepribadian yang mantap, stabil, dewasa, arif, dan berwibawa, menjadi teladan bagi peserta didik dan berakhlak mulia.

c. Kompetensi propesional, dalam standar nasional pendidikan, penjelasan pasal 28 nayat 3 butir C di kemukakan bahwa kompetensi professional adalah kemampuan penguasaan materi pembelajaran secara luas dan mendalam yang memungkinkan membimbing peserta didik memenuhi standar kompetensi yang di tetapkan dalam standar bnasional pendidikan.

d. Kompetensi sosial, dalam standar nasional pendidikan, penjelasan pasal 28 ayat 3 butir D dikemukakan bahwa kompetensi social adalah kemampuan guru sebagai bagian dari masyarakat untuk berkomunikasi dan bergaul secara efektif dengan peserta didik, sesame pendidik, tenaga kependidikan, orang tua/ wali peserta didik, dan masyarakat sekitar..

Berpijak pada konsep di atas dapat simpulkan bahwa seorang guru harus mengetahiu pribadi siswa, dimana siswa sebagai peserta didik merupakan salah satu input yang ikut menentukan keberhasilan proses pendidikan. Boleh dikatakan hampir semua kegiatan di sekolah pada akhirnya ditujukan untuk membantu siswa mengembangkan potensi dirinya. Boleh dikatakan hampir semua kegiatan di sekolah pada akhirnya ditujukan untuk membantu siswa mengembangkan potensi dirinya. Upaya itu akan optimal jika siswa sendiri secara aktif berupaya mengembangkan diri sesuai denagn program-program yang dilakukan oleh sekolah. Oleh karena itu, sangat penting untuk menciptakan kondisi agar siswa dapat mengembangkan diri secara optimal.

Begitu juga upaya yang dilakukan oleh guru Pendidikan Agama Islam di SDN 165 dalam meningkatkan hasil belajar PAI siswa kelas antara lain: meminta kepala sekolah untuk menampah jam di luar jam pelajaran PAI; melakukan komunikasi dengan wali siswa untuk mengingatkan anak mereka agar mengulang pelajaran di rumah; melakukan evaluasi sebelum dan sesudah pelajaran; memilih pendekatan/metode yang menarik bagi siswa; dan menggunakan media pembelajaran agar memudahkan menjelaskan materi dan mudah difahami oleh siswa.

\section{Penutup}

Upaya-upaya yang dilakukan oleh guru PAI SDN 165 Bangun Jaya dalam meningkatkan hasil belajar PAI siswa kelas antara lain: meminta kepala sekolah untuk menampah jam di luar jam pelajaran PAI; melakukan komunikasi dengan wali siswa untuk

${ }^{31}$ Ahmad Fawaid, "Rekontruksi Peran Guru Melalui Nilai-Nilai Al-Qur'an Di Era Modern," Ahsana Media 4, no. 2 (2018): 36-46; Sri Suyanta, "Signifikansi Qudwah Guru Dalam Pembelajaran Siswa SMP dan SMA di Aceh Utara," Jurnal MUDARRISUNA: Media Kajian Pendidikan Agama Islam 8, no. 1 (2018): 60-78; Arizqi Ihsan Pratama and Musthofa Musthofa, "Konsep Kepribadian Guru Menurut Ibnu Sahnun," Tawazun: Jurnal Pendidikan Islam 12, no. 1 (2019): 94-111.

32 Muhammad Yunus, "Profesionalisme Guru Dalam Peningkatan Mutu Pendidikan," Lentera Pendidikan: Jurnal Ilmu Tarbiyah Dan Keguruan 19, no. 1 (2016): 112-128; Nursalim Nursalim, "Profesionalisme Guru Sd/Mi," Lentera Pendidikan: Jurnal Ilmu Tarbiyah Dan Keguruan 20, no. 2 (2017): 250-256; Muh Hambali, "Manajemen Pengembangan Kompetensi Guru PAI,” Jurnal Manajemen Pendidikan Islam (J-MPI) 1, no. 1 (2016): 75-89.

Al-Ikhtibar: Jurnal Ilmu Pendidikan Volume 7 No. 2, Juli-Desember 2020 
mengingatkan anak mereka agar mengulang pelajaran di rumah; melakukan evaluasi sebelum dan sesudah pelajaran; memilih pendekatan/metode yang menarik bagi siswa; dan menggunakan media pembelajaran agar memudahkan menjelaskan materi dan mudah difahami oleh siswa dan menggunakan metode hadiah dan hukuman. Gambaran hasil pembelajaran PAI siswa kelas IV tergolong baik karena seluruh nilai siswa pada tahun ajaran 2019-2020 terlihat dari hasil semester mereka telah mencapai standar KKM yang ditetapkan. meskipun diakui bahwa masih ada sebagian siswa menemui kesulitan ketika bertemu dengan materi PAI yang berkaitan dengan lafaz-lafaz hurup hijaiyah. Kendala guru dalam meningkatkan hasil belajar PAI siswa kelas IV SDN 165 Bangun Jaya; media pembelajaran yang kurang tersedia di sekolah; kurangnya motivasi dan bimbingan orang tua di rumah dan masih ada beberapa siswa yang belum bisa dengan baik membaca lafaz-lafaz hijaiyah.

\section{Daftar Pustaka}

Alwasilah, Chaedar. "Pokoknya Kualitatif: Dasar-Dasar Rancangan Dan Melakukan Penelitian Kualitatif." Jakarta: Pustaka, 2011.

Anwar, Aep Saepul. "Pengembangan Sikap Profesionalisme Guru Melalui Kinerja Guru Pada Satuan Pendidikan MTs Negeri 1 Serang." Andragogi: Jurnal Pendidikan Islam Dan Manajemen Pendidikan Islam 2, no. 1 (2020): 147-173.

Anwar, Muhamad. Menjadi Guru Profesional. Prenada Media, 2018.

Bararah, Isna Wardatul. "Profesionalisme Dosen dalam Perspektif Islam dan Kontribusinya Terhadap Mutu Perguruan Tinggi." Jurnal MUDARRISUNA: Media Kajian Pendidikan Agama Islam 8, no. 2 (2018): 245-257.

Edu, Ambros, Florianus Arifin, and Mikael Nardi. Etika Dan Tantangan Profesionalisme Guru. Alfabeta Bandung, 2017.

Elihami, Elihami, and Abdullah Syahid. "Penerapan Pembelajaran Pendidikan Agama Islam Dalam Membentuk Karakter Pribadi Yang Islami." Edumaspul: Jurnal Pendidikan 2, no. 1 (2018): 79-96.

Fathurrohman, Muhammad. "Pengembangan Budaya Religius Dalam Meningkatkan Mutu Pendidikan." Ta'allum: Jurnal Pendidikan Islam 4, no. 1 (2016): 19-42.

Fawaid, Ahmad. "Rekontruksi Peran Guru Melalui Nilai-Nilai Al-Qur'an di Era Modern." Ahsana Media 4, no. 2 (2018): 36-46.

Hakim, Lukman. "Pemerataan Akses Pendidikan Bagi Rakyat Sesuai Dengan Amanat Undang-Undang Nomor 20 Tahun 2003 Tentang Sistem Pendidikan Nasional." EduTech: Jurnal Ilmu Pendidikan Dan Ilmu Sosial 2, no. 1 (March 30, 2016). https://doi.org/10.30596/edutech.v2i1.575.

Hambali, Muh. "Manajemen Pengembangan Kompetensi Guru PAI." Jurnal Manajemen Pendidikan Islam (J-MPI) 1, no. 1 (2016): 75-89.

Hatim, Muhammad. "Kurikulum Pendidikan Agama Islam Di Sekolah Umum." ELHIKMAH: Jurnal Kajian Dan Penelitian Pendidikan Islam 12, no. 2 (2018): 140-163.

Hendriana, Evinna Cinda, and Arnold Jacobus. "Implementasi Pendidikan Karakter di Sekolah Melalui Keteladanan dan Pembiasaan." JPDI (Jurnal Pendidikan Dasar Indonesia) 1, no. 2 (October 31, 2017): 25-29. https://doi.org/10.26737/jpdi.v1i2.262.

Hidayat, Rahmat, Muhammad Sarbini, and Ali Maulida. "Peran Guru Pendidikan Agama Islam Dan Budi Pekerti Dalam Membentuk Kepribadian Siswa SMK Al-Bana Cilebut 
Bogor.” Prosa PAI: Prosiding Al Hidayah Pendidikan Agama Islam 1, no. 1B (2018): 146-157.

Illahi, Nur. "Peranan Guru Profesional dalam Peningkatan Prestasi Siswa dan Mutu Pendidikan di Era Milenial.” Asy-Syukriyyah 21, no. 1 (2020): 1-20.

Imelda, Ade. "Implementasi Pendidikan Nilai Dalam Pendidikan Agama Islam." AlTadzkiyyah: Jurnal Pendidikan Islam 8, no. 2 (2017): 227-47. https://doi.org/10.24042/atjpi.v8i2.2128.

Juliansyah, Juliansyah. "Kritik Filosofis Atas Tujuan, Visi, dan Misi Mempertanyakan Mutu Pendidikan Nasional." Jurnal Lentera Bisnis 1, no. 1 (2017): 65-77.

Kurniawan, Fajar. "Pengembangan Teori Pendidikan Islam Perspektif Muhammad Jawwad Ridla (Religius Konservatif, Religius Rasional, Pragmatis Instrumental)." At-Ta'lim: Media Informasi Pendidikan Islam 18, no. 1 (2019): 223-242.

Marliu, Farizal, Otong Surasman, and Taufan Taufan. "Keteladanan Guru dan Pendidikan Dalam Keluarga Terhadap Kepribadian Muslim Siswa di MTs Pondok Pesantren AlHusainy Kota Bima." Tajdid: Jurnal Pemikiran Keislaman Dan Kemanusiaan 4, no. 1 (2020): 29-40.

Marwati, Marwati, and M. Ridwan Said Ahmad. "Peran Guru dalam Menerapkan Pendidikan Karakter di SMA Islam Al-Azhar 12 Makassar.” Jurnal Sosialisasi, 2019, 57-62.

Maya, Rahendra. "Esensi Guru Dalam Visi-Misi Pendidikan Karakter." Edukasi Islami: Jurnal Pendidikan Islam 2, no. 03 (2017).

Miles, Matthew B., A. Michael Huberman, and Johnny Saldaña. Qualitative Data Analysis: A Methods Sourcebook. 3rd. Thousand Oaks, CA: Sage, 2014.

Miles, Matthew B., M. A. Huberman, and Johnny Saldana. "Drawing and Verifying Conclusions. Qualitative Data Analysis: A Methods Sourcebook," 2014.

Moleong, Lexi J. Methodology of Qualitative Research. Bandung: Remaja Rosda Karya, 2010.

Nawali, Ainna Khoiron. "Dampak Penerapan Kurikulum Kementerian Agama dan Kurikulum Pesantren Terhadap Peningkatan Hasil Belajar PAI di MAN YOGYAKARTA.” AlIkhtibar: Jurnal Ilmu Pendidikan 5, no. 1 (2018): 555-575.

Normawati, Syarifah, and Siti Marpuah. "Kerangka Pembangunan Karakter Dalam Pembentukan Kreativiti Remaja di Sekolah Menengah Pertama Kota Batam." Human Sustainability Procedia, 2018.

Nursalim, Nursalim. "Profesionalisme Guru Sd/Mi." Lentera Pendidikan: Jurnal Ilmu Tarbiyah Dan Keguruan 20, no. 2 (2017): 250-256.

Pratama, Arizqi Ihsan, and Musthofa Musthofa. "Konsep Kepribadian Guru Menurut Ibnu Sahnun.” Tawazun: Jurnal Pendidikan Islam 12, no. 1 (2019): 94-111.

Rahmat, Pupu Saeful. "Peran Pendidikan dalam Menyiapkan Generasi Emas." Pendidikan Guru Sekolah Dasar S1 1, no. 01 (2016).

Ridwan, Wasis, and Ode Moh Man Arfa Ladamay. "Peran Guru Pendidikan Agama Islam Dalam Pembinaan Akhlakul Karimah Peserta Didik di Sma Muhammadiyah 8 Cerme Gresik." Tamaddun 21, no. 1 (April 4, 2020): 067-076. https://doi.org/10.30587/tamaddun.v21i1.1378. 
Roesli, Mohammad, Ahmad Syafi'i, and Aina Amalia. "Kajian Islam Tentang Partisipasi Orang Tua Dalam Pendidikan Anak." Jurnal Darussalam: Jurnal Pendidikan, Komunikasi Dan Pemikiran Hukum Islam 9, no. 2 (April 29, 2018): 332-45. https://doi.org/10.30739/darussalam.v9i2.234.

Roulston, Kathryn. "Analysing Interviews." The SAGE Handbook of Qualitative Data Analysis, 2014, 297-312.

Samae, Miss Saining, and S. Pd I. Istanto. "Pengaruh Keteladanan Guru Dalam Menanamkan Nilai Akhlak Siswa Di Madrasah Tsanawiyah Negeri 2 Surakarta." PhD Thesis, Universitas Muhammadiyah Surakarta, 2017.

Semiawan, Conny R. Metode Penelitian Kualitatif. Grasindo, 2010.

Sugiana, Aset. "Pengembangan Kurikulum Pendidikan Agama Islam Dan Implementasinya di MTs Nurul Ummah Yogyakarta.” Jurnal Pendidikan Agama Islam 16, no. 1 (June 5, 2019): 17-34. https://doi.org/10.14421/jpai.jpai.2019.161-02.

Sugiarto, Eko. Menyusun Proposal Penelitian Kualitatif: Skripsi dan Tesis: Suaka Media. Diandra Kreatif, 2017.

Supriadi, Dedi. "Pokoknya Kualitatif: Dasar-Dasar Merancang Dan Melakukan Penelitian Kualitatif." Jakarta: PT. Dunia Pustaka Jaya, 2011.

Suyanta, Sri. "Signifikansi Qudwah Guru Dalam Pembelajaran Siswa SMP dan SMA di Aceh Utara." Jurnal Mudarrisuna: Media Kajian Pendidikan Agama Islam 8, no. 1 (2018): 60-78.

Taufik, Irfan. "Penerapan Model Pembelajaran Contextual Teaching and Learning (CTL) Dalam Meningkatkan Hasil Belajar." IQRO: Journal of Islamic Education 2, no. 2 (2019): 163-174.

Wahono, Margi. "Pendidikan Karakter: Suatu Kebutuhan Bagi Mahasiswa Di Era Milenial." Integralistik 29, no. 2 (2018): 145-151.

Warsah, Idi. "Interkoneksi Pemikiran Al-Ghazāli Dan Sigmund Freud Tentang Potensi Manusia." Kontekstualita 32, no. 01 (January 26, 2018). http://ejournal.lp2m.uinjambi.ac.id/ojp/index.php/Kontekstualita/article/view/30.

. "Pendidikan Keimanan Sebagai Basis Kecerdasan Sosial Peserta Didik: Telaah Psikologi Islami." Psikis : Jurnal Psikologi Islami 4, no. 1 (June 8, 2018): 1-16. https://doi.org/10.19109/psikis.v4i1.2156.

Warsah, Idi, and Nuzuar Nuzuar. "Analisis Inovasi Administrasi Guru Dalam Meningkatkan Mutu Pembelajaran (Studi Man Rejang Lebong).” Edukasi 16, no. 3 (2018): 294572.

Warsah, Idi, and Muhamad Uyun. "Kepribadian Pendidik: Telaah Psikologi Islami." Psikis : Jurnal Psikologi Islami 5, no. 1 (June 18, 2019): 62-73. https://doi.org/10.19109/Psikis.v5i1.3157.

Yulianti, Hesti, Cecep Darul Iwan, and Saeful Millah. "Penerapan Metode Giving Question And Getting Answer Untuk Meningkatkan Hasil Belajar Peserta Didik Pada Mata Pelajaran Pendidikan Agama Islam.” Jurnal Penelitian Pendidikan Islam,[SL] 6, no. 2 (2018): 197-216.

Yunus, Muhammad. "Profesionalisme Guru Dalam Peningkatan Mutu Pendidikan." Lentera Pendidikan: Jurnal Ilmu Tarbiyah Dan Keguruan 19, no. 1 (2016): 112-128. 
Zakaria, Indra. "Penanaman Sikap Sopan Santun Melalui Keteladanan Guru di Smp Negeri 1 Buduran Kabupaten SidoarjO.” Kajian Moral Dan Kewarganegaraan 2, no. 4 (2016).

Zein, Muh. "Peran Guru Dalam Pengembangan Pembelajaran.” Inspiratif Pendidikan 5, no. 2 (2016): 274-285. 